\title{
A recommendation for suitable technologies for an indoor farming framework
}

\author{
C. Gnauer, H. Pichler, C. Schmittner, M. Tauber, K. Christl, J. Knapitsch, M. Parapatits
}

Facing food insecurity and overuse of resources due to effects of climate change, humanity needs to find new ways to secure food production and produce close to consumers. Vertical farming, where plants are grown in vertical arrays inside buildings with help of Information and Communication Technology (ICT) components, could contribute to solving this issue. Such systems integrate heterogeneous devices on different computing layers and acquire a lot of data to monitor and optimize the production process. We created an indoor testing unit in which growing conditions can be monitored and controlled to optimize growth of microgreens. This setup includes an Indoor Farming Support as a Service (IFSaaS) prototype that provides safe and secure monitoring and controlling, as well as self-adaption of an indoor farming system. In this article we provide information about the combination of most suitable technologies.

Keywords: vertical farming; indoor farming; loT; cloud computing

\section{Eine Empfehlung für geeignete Technologien für einen Indoor-Farming-Rahmen.}

Angesichts der Ernährungsunsicherheit und des übermäßigen Ressourcenverbrauchs aufgrund der Auswirkungen des Klimawandels muss die Menschheit neue Wege finden, um die Lebensmittelproduktion zu sichern und in der Nähe der Verbraucher zu produzieren. Die vertikale Landwirtschaft, bei der Pflanzen mithilfe von Komponenten der Informations- und Kommunikationstechnologie (IKT) in vertikaler Anordnung innerhalb von Gebäuden gezüchtet werden, könnte zur Lösung dieses Problems beitragen. Solche Systeme integrieren heterogene Geräte auf verschiedenen Rechenschichten und erfassen viele Daten, um den Produktionsprozess zu überwachen und zu optimieren. Wir haben eine Indoor-Testeinheit entwickelt, in der die Wachstumsbedingungen überwacht und gesteuert werden können, um das Wachstum von Microgreens zu optimieren. Dieses Setup beinhaltet einen IFSaaS-Prototyp (Indoor Farming Support as a Service), der eine sichere Überwachung und Steuerung sowie die Selbstanpassung eines Indoor-Farming-Systems ermöglicht. In diesem Artikel informieren wir Sie über die Kombination der am besten geeigneten Technologien.

Schlüsselwörter: vertikale Landwirtschaft; Indoor Farming; Internet der Dinge; Cloud Computing

Received July 17, 2020, accepted August 31, 2020, published online September 9, 2020

(C) The Author(s) 2020

\section{Introduction}

In the upcoming years the world population will grow steadily up to an estimated world population of 9.78 billion peak in 2064, yet decrease after that to 8.88 billion at the end of the century [1]. At the middle of the century about two thirds will live in urban areas [2]. This poses the issue to securely supply a growing number of people with food and imposes a great threat to food security for certain countries and especially for large cities. Several initiatives are targeted at this issue and one in particular, called vertical farming is discussed in this paper. This form of farming grows plants in vertical arrays, inside buildings, where growing conditions are optimized. Plants are supplied with nutrients via a specific solution and with artificial lighting and can thus be grown year round. Said method is able to grow without soil, natural sunlight and can therefore artificially create optimal growth conditions. With the help of Information Technology (IT) and Internet of Things (loT) components, the environment can be observed and adapted in a corrective way to create desired environmental parameters.

Vertical farming reuses resources more sustainably as water and nutrients can be reused and fewer fertilizers and no pesticides are needed [3], [4]. Food supply chains, often global, produce vast amounts of $\mathrm{CO}_{2}$ by transporting essential foods to large or remote cities. Indoor farming would tackle this form of emitting greenhouse gases through locally producing required food [5]. Shorter ways from harvesting to consumer can be achieved. We thus present a framework and indoor farming setup that addresses these issues. In our work we established a highly automated testing unit that allows for production of microgreens and other plants, e.g. salads. In our setup we focus on aeroponic [6] and deep water culture (DWC) [7] growing methods and how production processes can be optimized. To investigate approaches to optimize the growing methods and to evaluate optimization processes we established a testing environment at University of Applied Sciences Burgenland.

Gnauer, Clemens, Forschung Burgenland GmbH, Campus 1, 7000 Eisenstadt, Austria (E-mail: clemens.gnauer@forschung-burgenland.at); Pichler, Harald, Forschung Burgenland GmbH, Campus 1, 7000 Eisenstadt, Austria; Schmittner, Christoph, Austrian Institute of Technology GmbH, Giefinggasse 4, 1210 Vienna, Austria; Tauber, Markus, Fachhochschule Burgenland, Campus 1, 7000 Eisenstadt, Austria; Christl, Korbinian, Austrian Institute of Technology GmbH, Giefinggasse 4, 1210 Vienna, Austria; Knapitsch, Johannes, PhytonIQ GmbH, DI Rudolf Schober-Straße 4, 7400 Oberwart, Austria; Parapatits, Martin, PhytonlQ GmbH, DI Rudolf Schober-Straße 4, 7400 Oberwart, Austria 


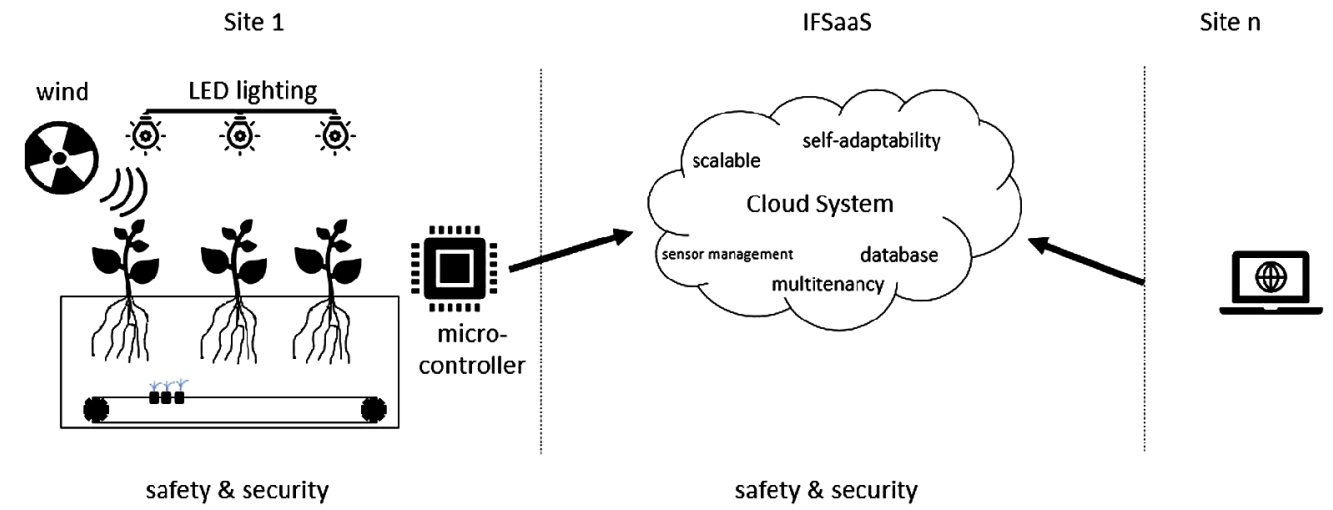

Fig. 1. Indoor Farming Support as a Service (IFSaaS) model

The paper is structured as follows: Sect. 2 gives an overview of related work, Sect. 3 introduces the indoor farming service we establish in the project. Sect. 4 describes the infrastructure setup we created for testing purposes and Sect. 5 concludes the paper.

\section{Related work}

The topic of vertical farming, e.g. aeroponic is not new [8]. On the other hand, its present state which uses IT and especially loT to monitor and control growth, is a rather recent development. Smart farming in general, with fine granular monitoring and control is only enabled by the introduction and wide-spread usage of Information and Communication Technology (ICT) solutions like sensor networks [9]. This allows for an optimization of the complete process. Combining this with vertical farming enables better use of space and thus output per square meter [10]. Therefore vertical farming approaches are also summarily called "Zero-Acreage Farming". This is especially important due to the increasing trend of urbanization. At the current point cities take up $2 \%$ of the earth surface, but require $75 \%$ of the available resources. Vertical farming is able to solve multiple issues, from a reduction in the resource usage to minimizing transportation costs [11]. Plants can be directly produced where they are consumed, in vertical buildings and throughout the year. Consequently, the large amount of fossil fuels consumed while transporting foods from rural farming areas can be reduced [12]. This requires localized vertical farming approaches with an optimization of the production output while minimizing required resources and space. One possible automation approach is autonomic management which we have already applied in related areas [13].

Newly projects often focus on holistic approaches that include not only farming technology but rather building design and structure and societal factors for acceptance of vertical farming projects [12]. Another factor is that agricultural land can be substituted and used to restore natural landscape and allow for much needed ecosystems to evolve [10]. Vertical farming technologies exist but still many factors rely on experience.

\section{Indoor Farming Support as a Service (IFSaaS)}

The target of the project Agri-Tec $4.0^{1}$ is to design and construct a cloud-based control system that provides a self adapting, yet safe and secure service for indoor farming. The goal is to develop an Indoor Farming Support as a Service(IFSaaS) prototype that allows for a safe and secure integration of multiple heterogeneous devices and

${ }^{1}$ https://www.forschung-burgenland.at/it/agrited/, accessed 29.07.2020. optimization of the growing process. The service is focused on security aspects of loT systems and thus integrations of a large amount of constrained devices. These measure and further control environmental conditions such as temperature, wind, etc. The cloud system enables integration of multiple sites and focuses on multitenancy, self-adaption of the growing units and scalability of the overall system. Setting it up in this way also allows to have a localized production (e.g. near consumption points) with a centralized and overarching control for multiple sites. The model for the IFSaaS is presented in Fig. 1.

For this purpose a combination of different computing layers are used. The upmost layer is the cloud layer that inhabits servers for data storage and controlling of underlying systems as well as for setting up a Virtual Private Network (VPN). The underlying layer is comprised of edge routers in the form of Raspberry Pi Model $4{ }^{2} \mathrm{~s}^{2}$ that contain ioBroker ${ }^{3}$ and Node-Red. ${ }^{4}$ These allow for data processing and storage. The last layer comprises of various fog nodes in the form of microcontrollers, e.g. Merkurboard, ${ }^{5}$ that measure and control the environment parameters via sensors and actuators. For a visual depiction see Fig. 2.

\section{Evaluated and combined technology for indoor farming} In this section we present our test environment for indoor farming in which we integrated a set of evaluated technologies. A black box, nicknamed Cubus, with dimensions of approximately $2.5 \times 3 \times 2.5$ (length $\mathrm{x}$ width $\mathrm{x}$ height) meters was designed and constructed at the premises. It essentially embodies a closed environmental chamber in which optimal conditions for indoor farming are established. Moreover, the Cubus contains the necessary IT and IOT infrastructure. A steel framework represents the basis and is supported and coated by textured coated boards. Each side contains three steel frames that can be opened up like doors and that are coated with a water-repellent fabric to allow for humidity to be kept inside the Cubus. The floor again consists of water-repellent material in case water leaks. On one side there are two shelves which contain IT, IOT and other technical infrastructure (screens) and growing equipment. There are also four deep water culture beds for growing salads. A

${ }^{2}$ https://www.raspberrypi.org/products/raspberry-pi-4-model-b/, accessed 29.07.2020

${ }^{3}$ https://www.iobroker.net/, accessed 14.07.2020.

${ }^{4}$ https://nodered.org/, accessed 14.07.2020.

${ }^{5}$ https://www.iot-shop.at/products/merkurboard, accessed 14.07.2020. 


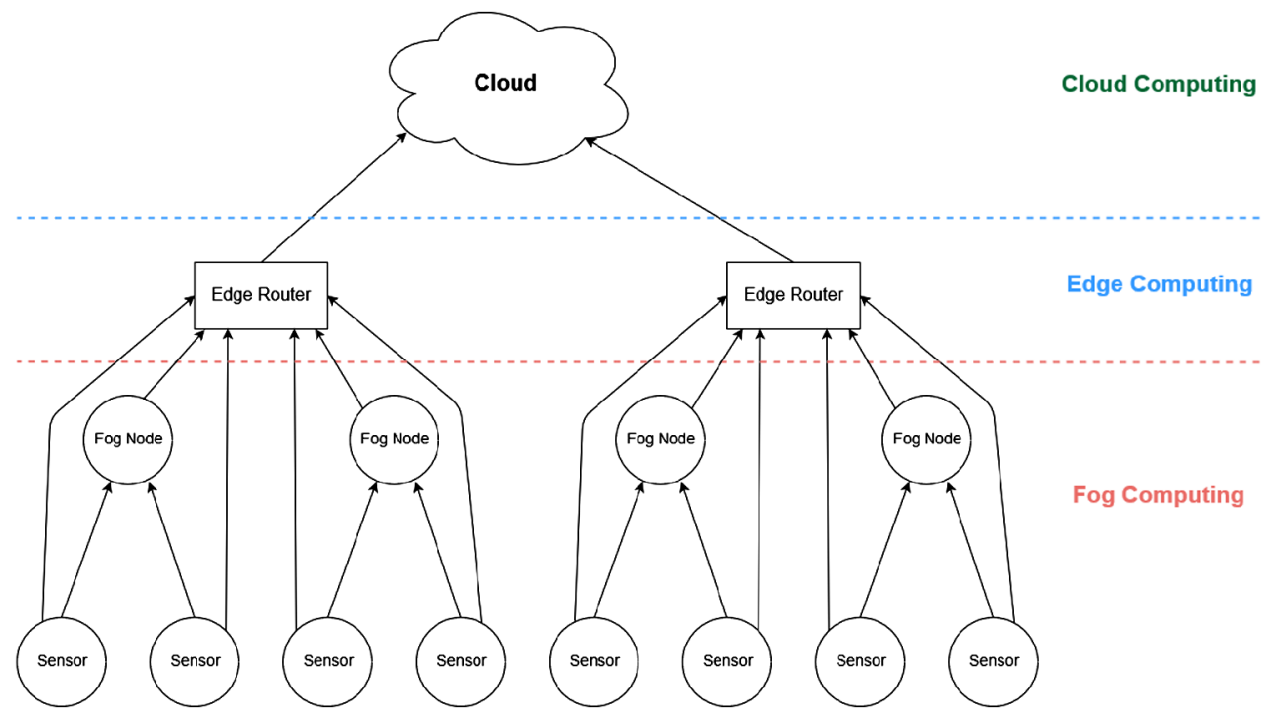

Fig. 2. Schematic of computing layers in AgriTec 4.0

mobile air condition system, ventilators and humidifiers ensure desired humidity and temperature.

The current IT infrastructure setup consists of a router, a switch, an edgerouter (Raspberry Pi 4), multiple constrained devices and the AgroRobot [8]. For remote visual inspections, a Raspberry Pi camera was installed to display the growing beds. The constrained devices, e.g. Merkurboards, are attached on the growing beds. These boards are battery powered devices that use ContikiOS [14], [15] as an operating system and communicate wirelessly with IEEE $802.15 .4{ }^{6}$ or 6 LoWPAN [8]. This protocol enables low energy communication over IPv6. The Constrained Application Protocol (CoAP) is further used as it uses URIs similar to HTTP and is ideal for machine to machine (M2M) communication [16]. Routing Protocol for Low power and Lossy Networks (RPL) [17] is used for the mesh network setup to enable fault-tolerant communication if individual nodes fail. Raspberry $\mathrm{Pi} 4 \mathrm{~s}$ act as edgerouters for the Merkurboards and process the sensory data to the cloud system. For control aspects of the IFSaaS we implemented ioBroker. ${ }^{7}$ It is a widely used and robust open source IOT platform with multiple ready to use interfaces. In combination with Node-RED, a rapid prototyping tool, it allows us to design and implement control loops for self-adaption. These are designed to optimize the growing process inside the cubus, by processing continuous measurements of environmental factors like humidity, temperature, wind, etc. and activating measures to influence them, e.g. turn on humidifier. Another possible technology for secure and trustworthy communication of the loT Components is the Arrowhead Framework [18].

A robotic appliance, named AgroRobot, made of a 3D printer motor and food-safe components inhabits six 3D printed growing trays for microgreens. This aeroponic system uses a vertically moving spraying lance to water plant roots with nutrient solution. It is currently controlled by an Arduino $\mathrm{Nano}^{8}$ and further operates the water pump and artificial lighting of the setup. The AgroRobot can further be controlled via a touchscreen. The visual setup was de-

\footnotetext{
${ }^{6}$ http://www.ieee802.org/15/pub/TG4.html, accessed 14.04.2020.

${ }^{7}$ https://www.iobroker.net/, accessed 14.07.2020.
}

${ }^{8}$ https://store.arduino.cc/arduino-nano, accessed 14.04.2020.

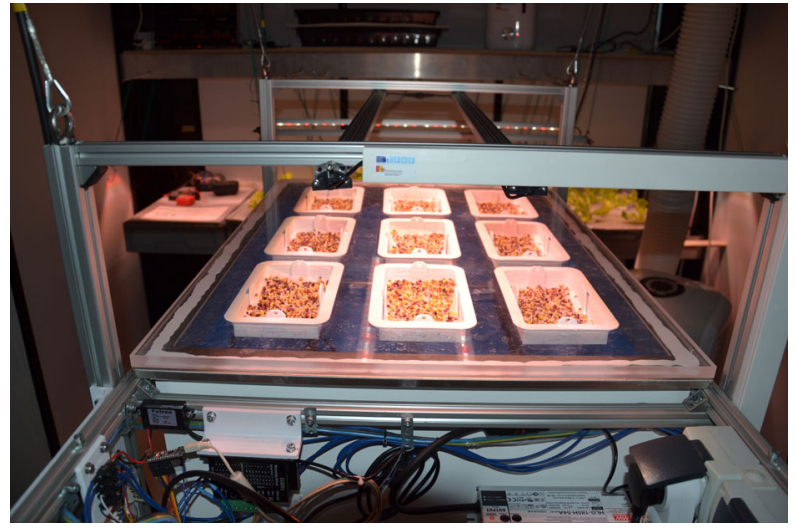

Fig. 3. Seeding of microgreens in AgroRobot, in background deep water culture(DWC) beds with salad

signed with Nextion. ${ }^{9}$ For a picture of AgroRobot inside the Cubus see Fig. 3.

\section{Conclusion}

Taking into account the progress and optimization enabled by the application of ICT, which complements the benefits of vertical farming there is a huge potential regarding environmental protection. In addition, climate change has the potential to threaten food security due to a more dynamic and unforeseeable climate [19]. Vertical farming with the independence from natural climate has here not only the potential to minimize the footprint of food production and to optimize the output for a given set of resources but also to stabilize food production. With investigating optimization approaches for vertical farming we support this approach in the future even more. The presented infrastructure will not only help us to evaluate optimization processes but also help others in reproduction for vertical farming setups. In the future, systems beyond aeroponics, e.g. aquaponic should also be investigated and their integration in the IFSaaS.

${ }^{9}$ https://nextion.tech/, accessed 15.07.2020 
Funding Note Open access funding provided by University of Applied Sciences Burgenland. The research has been carried out in the context of the project Agri-Tec 4.0 (FE06), funded by IWB-EFRE 2014-2020.

Publisher's Note Springer Nature remains neutral with regard to jurisdictional claims in published maps and institutional affiliations.

Open Access Dieser Artikel wird unter der Creative Commons $\mathrm{Na}$ mensnennung 4.0 International Lizenz veröffentlicht, welche die Nutzung Vervielfältigung, Bearbeitung, Verbreitung und Wiedergabe in jeglichem Medium und Format erlaubt, sofern Sie den/die ursprünglichen Autor(en) und die Quelle ordnungsgemäß nennen, einen Link zur Creative Commons Lizenz beifügen und angeben, ob Änderungen vorgenommen wurden. Die in diesem Artikel enthaltenen Bilder und sonstiges Drittmaterial unterliegen ebenfalls der genannten Creative Commons Lizenz, sofern sich aus der Abbildungslegende nichts anderes ergibt. Sofern das betreffende Material nicht unter der genannten Creative Commons Lizenz steht und die betreffende Handlung nicht nach gesetzlichen Vorschriften erlaubt ist, ist für die oben aufgeführten Weiterverwendungen des Materials die Einwilligung des jeweiligen Rechteinhabers einzuholen. Weitere Details zur Lizenz entnehmen Sie bitte der Lizenzinformation auf http://creativecommons.org/licenses/by/4.0/deed.de.

\section{References}

1. Vollset, S. E., Goren, E., Yuan, C. W., Cao, J., Smith, A. E., Hsiao, T., ... \& Dolgert, A J.(2020): Fertility, mortality, migration, and population scenarios for 195 countries and territories from 2017 to 2100: a forecasting analysis for the Global Burden of Disease Study. The Lancet.

2. DESA, UN (2018): World urbanization prospects: the 2018 revision, key facts. New York: NY. Available online at: https://population.un.org/wup/Publications/ (Accessed 12.05.2020

3. Collado, E., Fossatti, A., Saez, Y. (2018): Smart farming: a potential solution towards a modern and sustainable agriculture in Panama. AIMS Agricult. Food, 4(2), 266-284.

4. Kalantari, F., Tahir, O. M., Joni, R. A., Fatemi, E. (2018): Opportunities and challenges in sustainability of vertical farming: a review. J. Landsc. Ecol., 11(1), 35-60.

5. Pinstrup-Andersen, P., Pandya-Lorch, R., Rosegrant, M. W. (2001): Global food security. In The unfinished agenda, IFPRI, Washington (pp. 7-17)

6. Lakhiar, I. A., Jianmin, G., Syed, T. N., Chandio, F. A., Buttar, N. A., Qureshi, W. A. (2018): Monitoring and control systems in agriculture using intelligent sensor techniques: a review of the aeroponic system. J. Sens., 2018, 8672769.

\section{Authors}

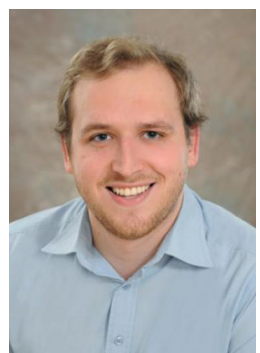

\section{Clemens Gnauer}

received his Master in Engineering in Cloud Computing at University of Applied Sciences Burgenland. He is a researcher at the Center for Cloud \& CPS Systems Security at Forschung Burgenland. Since 2018 he's contributing to the research project AgriTec 4.0 and administrates the CCPSS-Center infrastructure.

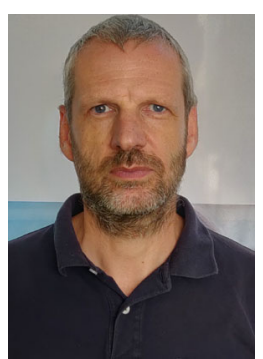

\section{Harald Pichler}

is working as a Key Researcher at Forschung Burgenland in the center for Cloud \& CPS System Security. Since 2018 he's leading the Project AgriTec 4.0 and developed the loT-Lab as part of the CCPSS-Center. In 2013 he received his M.Sc. at the FH Technikum, Wien on Smart-Home systems and has experience in loT, energy harvesting and embedded systems.
7. Sharma, N., Acharya, S., Kumar, K., Singh, N., Chaurasia, O. P. (2018): Hydroponics as an advanced technique for vegetable production: an overview. J. Soil Water Conserv., 17(4), 364-371.

8. Gnauer, C., Pichler, H., Tauber, M., Schmittner, C., Christl, K., Knapitsch, J., Parapatits, M. (2019): Towards a secure and self-adapting smart indoor farming framework. E\&l, Elektrotech. Inf.tech., 136(7), 341-344.

9. Walter, A., Finger, R., Huber, R., Buchmann, N., (2017): Opinion: smart farming is key to developing sustainable agriculture. In Proceedings of the National Academy of Sciences (pp. 6148-6150).

10. Despommier, D. (2013): Farming up the city: the rise of urban vertical farms. Trends Biotechnol., 31(7), 388-389.

11. Thomaier, S., Specht, K., Henckel, D., Dierich, A., Siebert, R., Freisinger, U. B., Sawicka, M. (2015): Farming in and on urban buildings: present practice and specific novelties of zero-acreage farming (ZFarming). Renewable Agricult. Food Syst., 30, 43-54.

12. Januszkiewicz, K., Jarmusz, M. (2017): Envisioning urban farming for food security during the climate change era. Vertical farm within highly urbanized areas. IOP conference series: materials science and engineering. (Vol. 245, No. 5). Bristol: IOP Publishing.

13. Maksuti, S., Schluga, O., Settanni, G., Tauber, M., Delsing, J. (2019): In Self-adaptation applied to MQTT via a generic autonomic management framework 20th IEEE international conference on industrial technology, 2019 (IEEE ICIT 2019), Melbourne, Australia, Feb. 2019

14. Durmaz, C., Challenger, M., Dagdeviren, O., Kardas, G. (2017): Modelling contikibased loT systems. In 6th symposium on languages, applications and technologies (SLATE 2017), Schloss Dagstuhl-Leibniz-Zentrum fuer Informatik

15. Zikria, Y. B., Afzal, M. K., Ishmanov, F., Kim, S. W., Yu, H. (2013): A survey on routing protocols supported by the Contiki Internet of things operating system. Future Gener. Comput. Syst., 82, 200-219.

16. Kovatsch, M., Duquennoy, S., Dunkels, A. (2011): A low-power CoAP for Contiki. In Workshop on Internet of things technology and architectures (IEEE loTech 2011).

17. Solapure, S. S., Kenchannavar, H. H. (2019): RPL and COAP protocols, experimental analysis for IOT: a case study. Int. J. Ad Hoc, 10(2), 1.

18. Bicaku, A., Maksuti, S., Hegedus, C., Tauber, M., Delsing, J., Eliasson, J. (2018): Interacting with the arrowhead local cloud: on-boarding procedure. In 1st IEEE international conference on industrial cyber-physical systems (IEEE ICPS 2018), Saint Petersburg, Russia, May 15-18, 2018

19. Lipper, L., Thornton, P., Campbell, B. M., Baedeker, T., Braimoh, A., Bwalya, M., Caron, P., Cattaneo, A., Garrity, D., Henry, K., et al.(2014): Climate-smart agriculture for food security. Nat. Clim. Change, 4, 1068-1072.

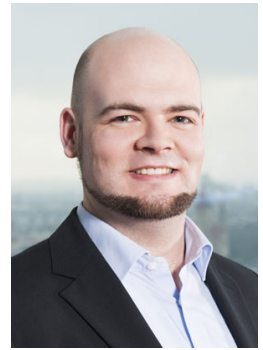

\section{Christoph Schmittner}

received his M.Sc. in System and Software Engineering at the University of Applied Sciences Regensburg in 2013. His main research area is safety and security co-engineering. He works on safety, security analysis and co-analysis methods, connected and safety critical/fault \& intrusion tolerant system architectures, functional safety and cybersecurity standards and inter-dependence of safety and security in critical systems.

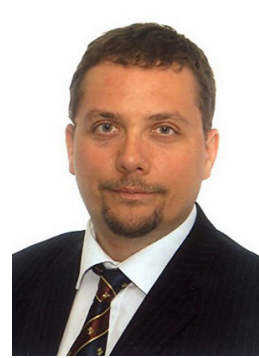

\section{Markus Tauber}

is a scholar and researcher with international experience in the area of networks and distributed systems with a focus on the engineering side of digitization. He has published more than 40 peer-reviewed articles on above topics. He currently works at the $\mathrm{FH}$ Burgenland leading the master's program Cloud Computing Engineering and the Research Center - Cloud and CPS Security. 


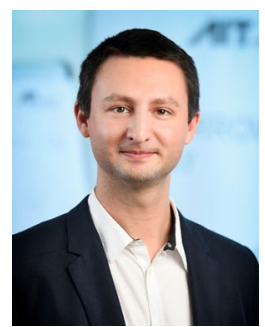

\section{Korbinian Christl}

is a Junior Research Engineer at the Austrian Institute of Technology. In 2016 Mr. Christl graduated in Business Computer Science at the University of Vienna, Austria. He is currently studying for a master's degree in general computer science and a member of the "Dependable Systems Engineering" Team of the AIT.

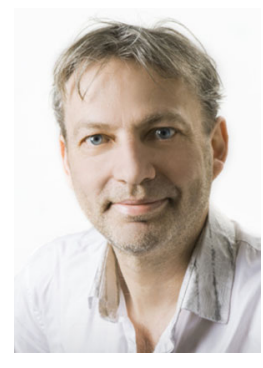

\section{Johannes Knapitsch}

is a technical engineer and CEO of PhytonIQ Technology. He has decades of experience in robotics, automotive development, LED technology, microcontroller HW and SW, as well as controlling and regulation. He worked in corporations as production manager of a solar cell factory and program director in the development of electronical components for the consumer area.

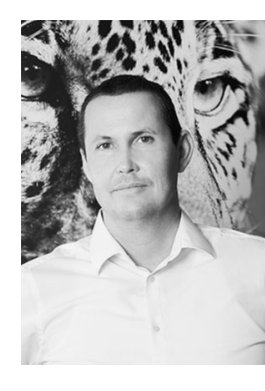

Martin Parapatits

the founder of PhytonlQ, has a broad, interdisciplinary knowledge in different fields of expertise, through his three completed studies in Civil Engineering(TU Vienna), Environmental Sciences (University of Hagen) and Astronomy (University of Vienna). His 20-year experience include technical aspects of building constructions, sales and acquisition activities. 